\title{
Incremental prognostic value of coronary flow reserve assessed with single-photon emission computed tomography
}

\author{
Robert A. deKemp, PhD, ${ }^{\mathrm{a}, \mathrm{b}}$ Mikael Trottier, MD, FRCPC, ${ }^{\mathrm{a}}$ and \\ Rob S. B. Beanlands, MD, FACC, FRCPC ${ }^{a}$
}

\section{See related article, pp. 612-619}

The diagnostic and prognostic values of stress myocardial perfusion imaging (MPI) is well established with SPECT ${ }^{1-12}$ and more recently with PET or PET-CT imaging. ${ }^{13-15}$ Conventional MPI identifies local reductions in perfusion relative to the best ventricular wall, where the maximum value is presumed to be normal. However, this technique is known to underestimate the extent or severity of multi-vessel coronary disease, when the maximum value does not represent normally perfused myocardium. ${ }^{16,17}$ In contrast, myocardial perfusion measured on an absolute scale $(\mathrm{mL} / \mathrm{min} / \mathrm{g}$ ) permits the assessment of stress-to-rest perfusion or vasodilator reserve without the assumption of a normal reference region, first demonstrated with PET imaging by Gould et al $^{18}$ In this way, the stress perfusion scan is interpreted relative to the individual's normal resting state, using the patient as their own control. The clinical value of absolute perfusion or myocardial blood flow (MBF) measurements has been reported extensively using dynamic PET imaging with ${ }^{15} \mathrm{O}$-water and ${ }^{13} \mathrm{~N}$ ammonia in patient populations such as diabetes, hypertension, hyperlipidemia, smoking, syndrome $\mathrm{X}$, non-compaction, takotsubo, hypertrophic , and dilated cardiomyopathies. The impact of invasive fractional flow reserve (FFR) imaging to direct PCI and improve patient outcome has recently been reported using FFR

From the Division of Cardiology, ${ }^{\text {a }}$ Cardiac Imaging, ${ }^{\mathrm{b}}$ The National Cardiac PET Centre, University of Ottawa Heart Institute, Ottawa, ON, Canada.

Reprint requests: Robert A. deKemp, PhD, Cardiac Imaging, The National Cardiac PET Centre, University of Ottawa Heart Institute, 40 Ruskin Street, Ottawa, ON K1Y 4W7, Canada; radekemp@ ottawaheart.ca.

J Nucl Cardiol 2011;18:541-3.

$1071-3581 / \$ 34.00$

Copyright (c) 2011 American Society of Nuclear Cardiology.

doi:10.1007/s12350-011-9408-6 measurements in a prospective randomized controlled trial. $^{19}$

However, there is limited data available on the value of non-invasive myocardial flow reserve (MFR) imaging to improve patient management, or predict future clinical events, compared to conventional MPI. This is partly due to the limited availability of ${ }^{13} \mathrm{~N}$ ammonia and ${ }^{15} \mathrm{O}$-water $\mathrm{PET}$, which require a local cyclotron for tracer production. Tio et $\mathrm{al}^{20}$ recently reported on the prognostic value of ${ }^{13} \mathrm{~N}$-ammonia PET flow reserve imaging in patients with known coronary artery disease and LV dysfunction who did not undergo revascularization. This study showed that MFR was a stronger predictor of cardiac death compared to LVEF in this population (HR 4.1 vs 2.8; 7 years median followup), but did not assess the incremental value compared to standard MPI. Herzog demonstrated similar findings that impaired MFR (ratio <2) was an independent predictor of cardiac death (HR 2.9; 5.5 years mean follow-up) using ${ }^{13} \mathrm{~N}$-ammonia PET in a wider unselected population. ${ }^{21}$ This study also showed the incremental prognostic value of MFR over standard MPI in patients with known or suspected CAD, more typical of the clinical population referred for assessment of myocardial ischemia. In patients with normal MPI, impaired MFR was an independent predictor of cardiac death (3.1 vs $0.5 \%$ ) and major adverse cardiac events (MACE; 6.3 vs $1.4 \%$ ) within a period of 3 years. In patients with abnormal MPI, impaired MFR also predicted an increased rate of disease progression, even beyond 3 years. A larger patient series, followed for a shorter time, has recently confirmed the incremental prognostic value of generator-produced ${ }^{82} \mathrm{Rb}$ PET MFR to predict death or myocardial infarction (death $+\mathrm{MI}$; $\mathrm{HR} \geq 3.3)$ and MACE $(\mathrm{HR} \geq 2.4$; 1-year median follow-up) in patients with normal or abnormal stress MPI. $^{22}$

The current study by Stephania et $\mathrm{al}^{23}$ builds on these previous findings using ${ }^{99 \mathrm{~m}}$ Tc-SPECT, which is more widely available as the clinical standard for MPI. The authors use first-pass planar imaging followed by conventional SPECT MPI to estimate a retention index of $\mathrm{MBF}$ and corresponding global flow reserve. They 
showed that in patients with normal MPI, reduced global flow reserve was associated with higher annual rates of major adverse cardiac events $(5.2 \%$ vs $0.7 \%$; 5.8 years mean follow-up) consistent with previous PET studies.

Some differences between the SPECT and PET results may be attributed to important variations in the flow reserve imaging methodologies, and affect the ability to incorporate routine MFR measurements into the clinical practice of MPI. This study reported a substantially higher rate of abnormal MFR (65\%) in patients with normal MPI, compared to the previous PET studies (24\%-31\%). This is likely due to the use of a retention index instead of absolute MBF for flow reserve estimation, as illustrated in Figure 1. If the tracer retention rate is measured in $\mathrm{mL} / \mathrm{min} / \mathrm{g}$, then quantitative estimates of MBF and flow reserve can be derived by correcting for the retention fraction which decreases non-linearly with MBF. However, this correction is not possible when tracer retention is measured in arbitrary units (a.u.). The tracer retention fraction decreases progressively with increasing blood flow, therefore some underestimation in flow reserve will occur using a retention index approach. Since this study used a retention reserve cutoff value $<2$ as abnormal, this may explain the relatively high rate of abnormal flow reserve findings. This suggests that more than half the patients classified as abnormal by SPECT may have been considered normal using PET flow methods, possibly accounting for the slightly lower event rate of 5.2\%/year in this study compared to $6.3 \%$ in the study by Herzog. It also suggests a more strict definition of normal MFR in this study, explaining the very low event rate of $0.7 \% /$ year compared to $1.4 \%$ by Herzog, in patients with normal MPI and MFR combined. Therefore, a lower cutoff value for identification of impaired reserve should be considered in studies using retention index estimates of MBF.

This study did not adjust resting MBF values for changes in heart-rate-pressure-product (RPP). This is consistent with previous PET prognosis studies, which have not demonstrated an independent effect of resting blood pressure or RPP on patient outcomes. Normal resting MBF is known to decrease with the age-dependent increase in blood pressure and heart rate. ${ }^{24}$ Therefore, it is common with PET to adjust resting flow values to a reference heart-rate-pressure-product (RPP) before calculating MFR $_{\mathrm{ADJ}}$ for investigation of diseasespecific pathologies. However, it is possible that the effect of hypertension to increase resting MBF and reduce MFR with increasing age may be a contributing factor to the increased rate of cardiac events predicted by impaired flow reserve.

Translation of a new diagnostic test such as flow reserve quantification into a routine clinical tool requires

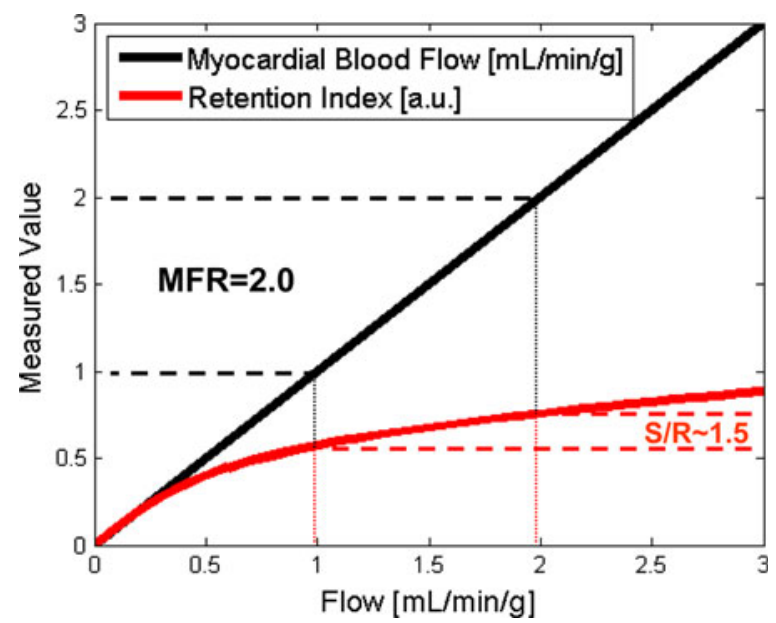

Figure 1. Myocardial flow reserve (MFR) and stress/rest retention ratio $(\mathrm{S} / \mathrm{R})$ illustrated for typical rest and stress flow values ( 1 and $2 \mathrm{~mL} / \mathrm{min} / \mathrm{g}$, respectively). Myocardial flow reserve is underestimated by measurements of tracer retention index in arbitrary units (a.u.).

several key features. These include: (i) reproducibility and validation in animal models and in humans, (ii) availability of both the tracer and imaging technology, (iii) ease of implementation in clinical practice, (iv) proven added value for diagnostic or prognostic application and/or impact on therapy decisions and patient outcomes. Despite some methodological variations in the flow reserve studies reported to date, there is now increasing evidence using both SPECT and PET techniques, to suggest that a "warranty period" of 2 years (e.g., $<2 \%$ risk of death + MI) following normal MPI may be extended to $>3$ years or shortened to $<1$ year according to the corresponding MFR results. The small study sample size used in the present investigation (99 patients), as well as in previous retrospective PET prognosis studies, highlights the need for additional prospective evaluation studies in larger populations to confirm the positive impact of routine MFR combined with MPI imaging on patient management and clinical outcomes. In particular, it will be important to discriminate between patients with impaired flow reserve due to multi-vessel obstructive coronary artery disease vs those with micro-vascular disease, to select the most appropriate and effective therapy for each.

\section{References}

1. Hachamovitch R, Hayes S, Friedman JD, Cohen I, Shaw LJ, Germano G, et al. Determinants of risk and its temporal variation in patients with normal stress myocardial perfusion scans: What is the warranty period of a normal scan? J Am Coll Cardiol 2003;41:1329-40.

2. Hachamovitch R, Hayes SW, Friedman JD, Cohen I, Berman DS. Stress myocardial perfusion single-photon emission computed 
tomography is clinically effective and cost effective in risk stratification of patients with a high likelihood of coronary artery disease (CAD) but no known CAD. J Am Coll Cardiol 2004;43:200-8.

3. Berman DS, Hachamovitch R, Kiat H, et al. Incremental value of prognostic testing in patients with known or suspected ischemic heart disease: A basis for optimal utilization of exercise technetium-99m sestamibi myocardial perfusion single-photon emission computed tomography. J Am Coll Cardiol 1995;26:639-47.

4. Hachamovitch R, Berman DS, Kiat H, et al. Exercise myocardial perfusion SPECT in patients without known coronary artery disease: Incremental prognostic value and use in risk stratification. Circulation 1996;93:905-14.

5. Hachamovitch R, Berman DS, Shaw LJ, et al. Incremental prognostic value of myocardial perfusion single photon emission computed tomography for the prediction of cardiac death: Differential stratification for risk of cardiac death and myocardial infarction. Circulation 1998;97:535-43.

6. Shaw LJ, Berman DS, Hachamovitch R, et al. Noninvasive strategies for the estimation of cardiac risk: An observational assessment of outcome in stable chest pain patients. Am J Cardiol 2000;86:1-7.

7. Gibbons RJ, Hodge DO, Berman DS, et al. Long-term outcome of patients with intermediate-risk exercise electrocardiograms who do not have myocardial perfusion defects on radionuclide imaging. Circulation 1999;23:2140-5.

8. Iskander S, Iskandrian AE. Risk assessment using single-photon emission computed tomographic technetium-99m sestamibi imaging. J Am Coll Cardiol 1998;32:57-62.

9. Groutars RG, Verzijlbergen JF, Zwinderman AH, et al. Incremental prognostic value of myocardial SPET with dual-isotope rest 201T1/stress 99mTc-tetrofosmin. Eur J Nucl Med 2002;29:4652.

10. Groutars RG, Verzijlbergen JF, Muller AJ, et al. Prognostic value and quality of life in patients with normal rest thallium-201/stress technetium 99m-tetrofosmin dual-isotope myocardial SPECT. J Nucl Cardiol 2000;7:333-41.

11. Galassi AR, Azzarelli S, Tomaselli A, et al. Incremental prognostic value of technetium-99m-tetrofosmin exercise myocardial perfusion imaging for predicting outcomes in patients with suspected or known coronary artery disease. Am JCardiol 2001; 88:101-6.

12. Shaw LJ, Hendel R, Borges-Neto S, Lauer MS, Alazraki N, et al. Prognostic value of normal exercise and adenosine $99 \mathrm{mTc}$-tetrofosmin SPECT imaging: Results from the Multicenter Registry of 4,728 patients. J Nucl Med 2003;44:134-9.

13. Bateman TM, Heller GV, McGhie AI, Friedman JD, et al. Diagnostic accuracy of rest/stress ECG-gated Rb-82 myocardial perfusion PET: Comparison with ECG-gated Tc-99m sestamibi SPECT. J Nucl Cardiol 2006;13:24-33.

14. Yoshinaga K, Chow BJ, deKemp RA, Beanlands R, et al. What is the prognostic value of myocardial perfusion imaging using rubidium-82 positron emission tomography? J Am Coll Cardiol 2006;48:1029-39.

15. Sampson UK, Di Carli MF, Dorbala S, Kwong R, et al. Diagnostic accuracy of rubidium-82 myocardial perfusion imaging with hybrid positron emission tomography/computed tomography in the detection of coronary artery disease. J Am Coll Cardiol 2007;49:1052-8.

16. Parkash R, deKemp RA, Beanlands RS, et al. Potential utility of rubidium-82 PET quantification in patients with 3-vessel coronary artery disease. J Nucl Cardiol 2004;11:440-9.

17. Ziadi MC, deKemp RA, Williams K, Guo A, Renaud JM, Klien R, et al. Does quantification of myocardial flow reserve using rubidium- 82 positron emission tomography facilitate detection of multivessel coronary artery disease? J Nucl Cardiol 2011 (submitted).

18. Goldstein RA, Kirkeeide RL, Demer LL, Merhige M, Nishikawa A, Smalling RW, et al. Relation between geometric dimensions of coronary artery stenoses and myocardial perfusion reserve in man. J Clin Invest 1987;79:1473-8.

19. Tonino PAL, De Bruyne B, Pijls NHJ, Siebert U, Ikeno F, van't Veer M, et al. Fractional flow reserve versus angiography for guiding percutaneous coronary intervention. $\mathrm{N}$ Eng $\mathrm{J}$ Med 2009;360:213-24.

20. Tio R, van Veldhuisen DJ, Zijlstra F, Slart RH, et al. Comparison between the prognostic value of left ventricular function and myocardial perfusion reserve in patients with ischemic heart disease. J Nucl Med 2009;50:214-9.

21. Herzog BA, Husmann L, Kaufmann PA, et al. Long-term prognostic value of ${ }^{13} \mathrm{~N}$-ammonia myocardial perfusion PET: Added value of coronary flow reserve. J Am Coll Cardiol 2009;54:150-6.

22. Ziadi MC, deKemp RA, Williams K, Guo A, Chow BJW, Renaud $\mathrm{JM}$, et al. Impaired myocardial flow reserve on rubidium-82 positron emission tomography imaging predicts adverse outcomes in patients assessed for myocardial ischemia. J Am Coll Cardiol 2011 (in press).

23. Stephania D, Nappi C, Acampa W, Storto G, Pellegrino T, Ricci F, et al. Incremental prognostic value of coronary flow reserve assessed with single photon emission computed tomography. J Nucl Cardiol 2011. doi:10.1007/s12350-011-9345-4.

24. Uren NG, Camici PG, Melin JA, Bol A, de Bruyne B, Radvan J, et al. Effect of aging on myocardial perfusion reserve. J Nucl Med 1995;36:2032-6. 